\title{
The National Institute of Standards and Technology (NIST) Celebrates its Centennial
}

This article was contributed by Dr. Robert N. Goldberg (Biotechnology Division, NIST, Gaithersburg, MD 20899, USA; E-mail: robert.goldberg@ @ist.gov), Secretary of the IUPAC Commission on Biophysical Chemistry (I.7), and Dr. David R. Lide, NIST alumnus and former President of the IUPAC Physical Chemistry Division (I).

\section{Introduction}

The National Institute of Standards and Technology (NIST) celebrates its centennial this year. NIST, formerly known as the National Bureau of Standards (NBS), was established in 1901 by the U.S. Congress to maintain custody of the national standards of measurement and to develop new ones as needed by the country's rapidly expanding industry. NIST/NBS has grown from a relatively small laboratory with approximately 12 employees to a major research laboratory. NIST has also had a long involvement with IUPAC in many areas of chemical research. The aim of this article is to give a brief history of NIST/NBS, with some discussion of its interactions with IUPAC.

Three excellent written histories of NIST/NBS exist. They include Measures for Progress: A History of the National Bureau of Standards, by R. C. Cochrane (National Bureau of Standards, U.S. Department of Commerce, Washington, DC, 1966, $2^{\text {nd }}$ Printing, 1974); A Unique Institution: The National Bureau of Standards, 1950-1969, by E. Passaglia and K. A. Beal (NIST Special Publication 925, U.S. Department of Commerce, Technology Administration, NIST, Washington, DC, for sale by the Superintendent of Documents, U.S. Government Printing Office, 1999); and $R e$ sponding to National Needs: The National Bureau of Standards Becomes the National Institute of Standards and Technology, 1969-1993, by J. F. Schooley (NIST Special Publication 955. U.S. Department of Commerce, Technology Administration, NIST, Washington, DC, for sale by the Superintendent of Documents, U.S. Government Printing
Office, 2000). The history described herein has been excerpted from these sources.

\section{Establishment of the National Bureau of Standards (NBS)}

The United States was a rapidly changing nation 100 years ago. The country had been primarily agricultural for most of the $19^{\text {th }}$ century, but had undergone extremely rapid industrial growth in the latter part of that century. By 1900, the United States was already a major industrial power, and electricity was arriving in many cities and towns. Articles of commerce require legally based standards to ensure fairness in trade, and there was clearly a need for standards for many physical quantities. In 1836, the United States had established a Bureau of Weights and Measures that maintained standards of mass, length, and volume. In 1884, the Bureau of Weights and Measures also adopted standards for electrical units. Yet, the work of the Bureau of Weights and Measures had very little legal standing, as this function was left to the individual states. Also, the United States had been one of the 17 original member states of the "Convention of the Metre" (1875) that led to the founding of the International Bureau of Weights and Measures (BIPM) in Paris. By the end of the $19^{\text {th }}$ century, several countries had established prominent national standards laboratories, among them the Physikalish-Technische Reichsanstalt (Germany, 1887) and the National Physical Laboratory (Great Britain, 1899). Surprisingly, at the turn of the last century, the

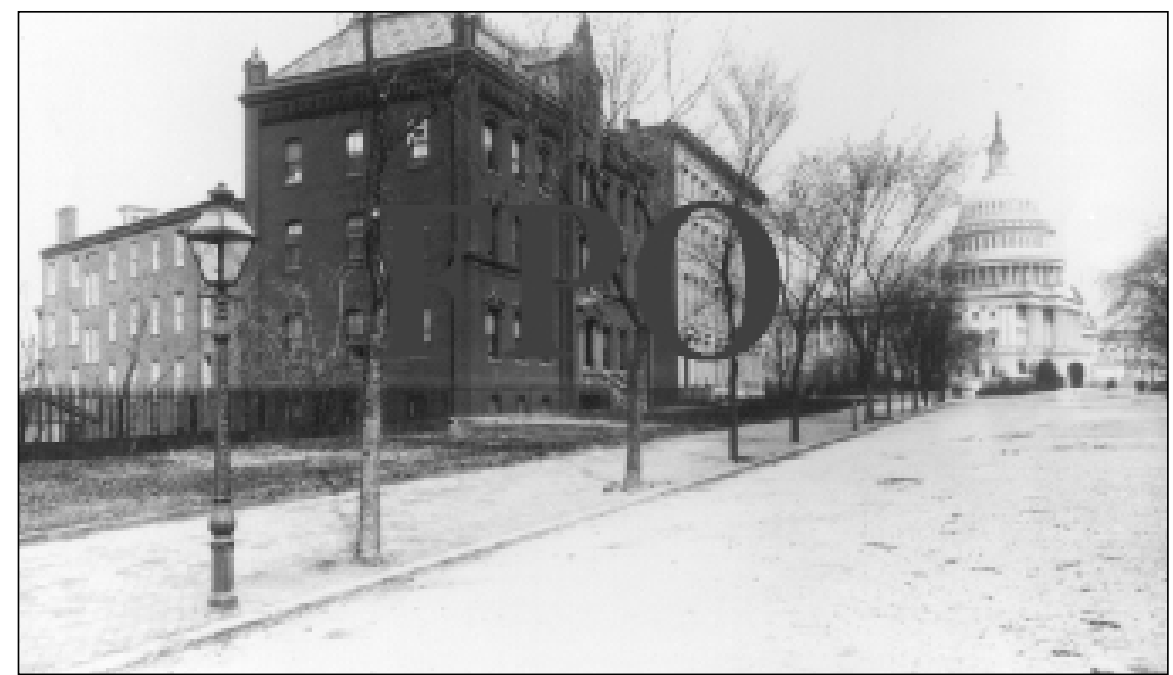

NBS occupied the former quarters of the Office of Weights and Measures in the Coast and Geodetic Survey Building shown here in 1901. 


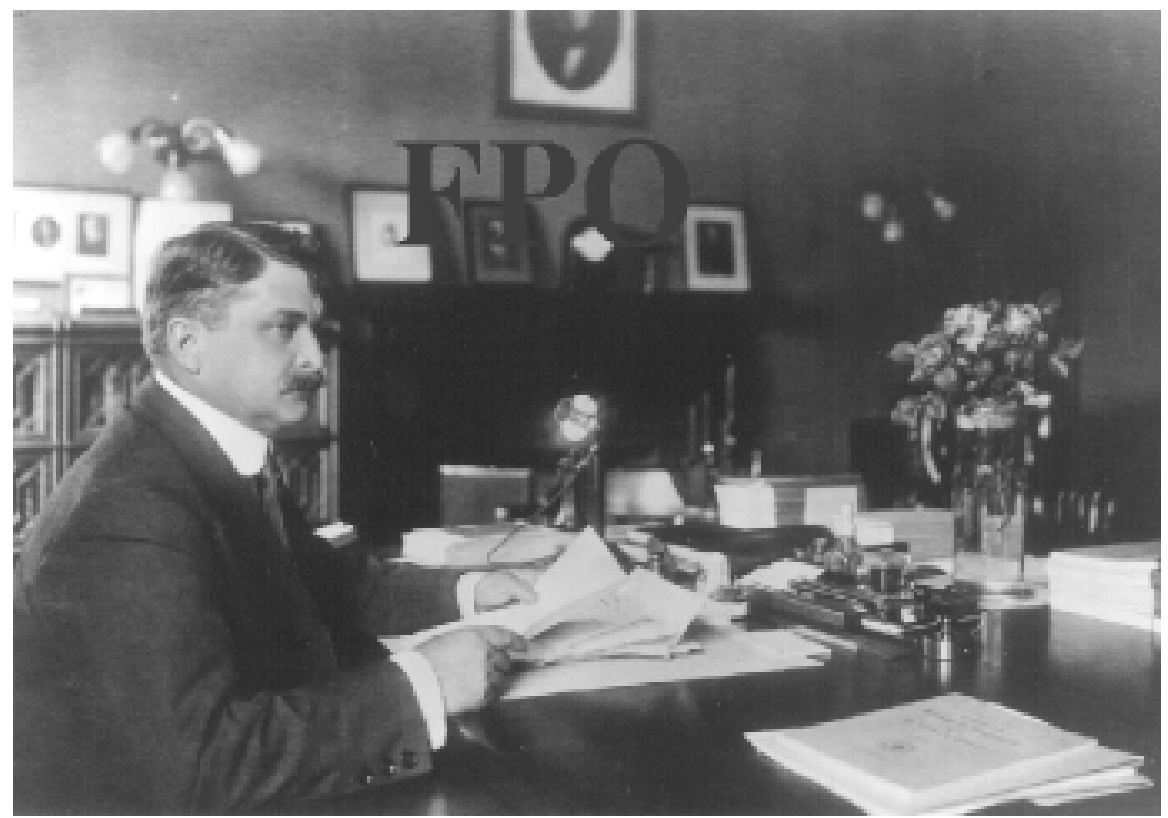

Samuel Wesley Stratton, the first director of NBS.

United States was the only great commercial nation without a significant standards laboratory. Thus, a convincing case for the establishment of a proper standards laboratory could easily be made on the basis of the rapidly changing nature of the nation's economy, a desire to aid the scientific enterprise, and a wish to be commensurate in this important activity with other modern nations in the new century. As indicated above, the need for standards was particularly acute in regard to the rapidly developing electrical industry. Thus, the administration of President McKinley pressed Congress for the establishment of a modern national standards laboratory. Enabling legislation was passed 3 March 1901, but did not become effective until 1 July 1901. The National Bureau of Standards (NBS) was originally established within the Department of the Treasury; it was moved to the newly formed Department of Commerce (and Labor) in 1904.

NBS was first located in the Coast and Geodetic Survey Building, which was the home of the Office of Weights and Measures in Washington, DC. The first director, Samuel Wesley Stratton, had been a professor of physics at the University of Chicago. He brought incredible talent and energy to the Bureau and worked hard to establish the new laboratory. The original staff consisted of approximately 12 individuals, but grew to about 800 during the nearly 22 years that he served as director before leaving in 1923 to become president of the Massachusetts Institute of Technology. During his tenure as NBS Director, Dr. Stratton enlisted a very distinguished staff that included well-known experts in various scientific disciplines: E. B. Rosa and Frank A. Wolff (electrical measurements); Charles W. Waidner, Nathan S. Osborne, and Hobart C. Dickinson (heat and thermometry); W. W. Coblentz and W. W. Bates (optics); and W. A. Noyes and W. F. Hillebrand (chemistry). The emphasis was to serve science and industry in the nation. While the scientific work of the Bureau became ever more well-known in scientific and technical circles, the general public often identified NBS with standards and calibrations. Additionally, NBS publications on subjects of interest to consumers and on popular science subjects attracted significant attention.

Early in 1904, NBS moved to its Connecticut Avenue location in Washington, DC, where it would remain for about 60 years. Relocation of the main labo-

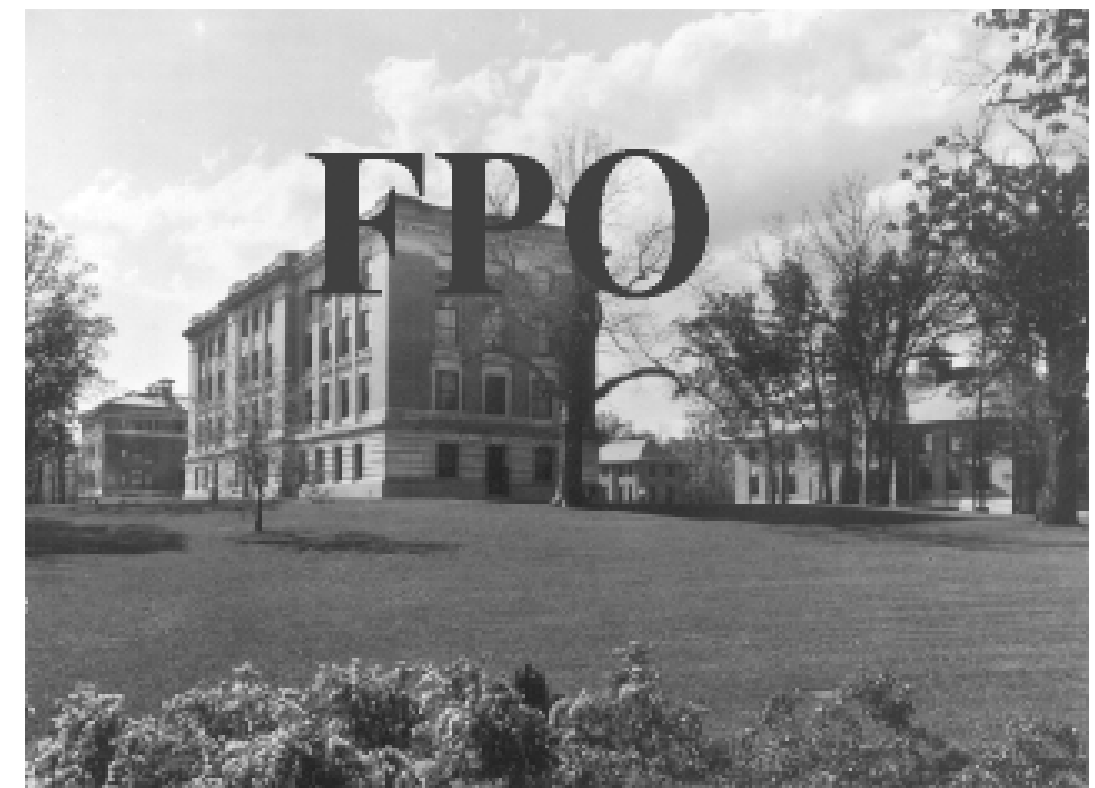

NBS occupied a 3-hectare site about $6 \mathrm{~km}$ north of the White House in 1910. Subsequent land purchases expanded the site to about 28 hectares. 


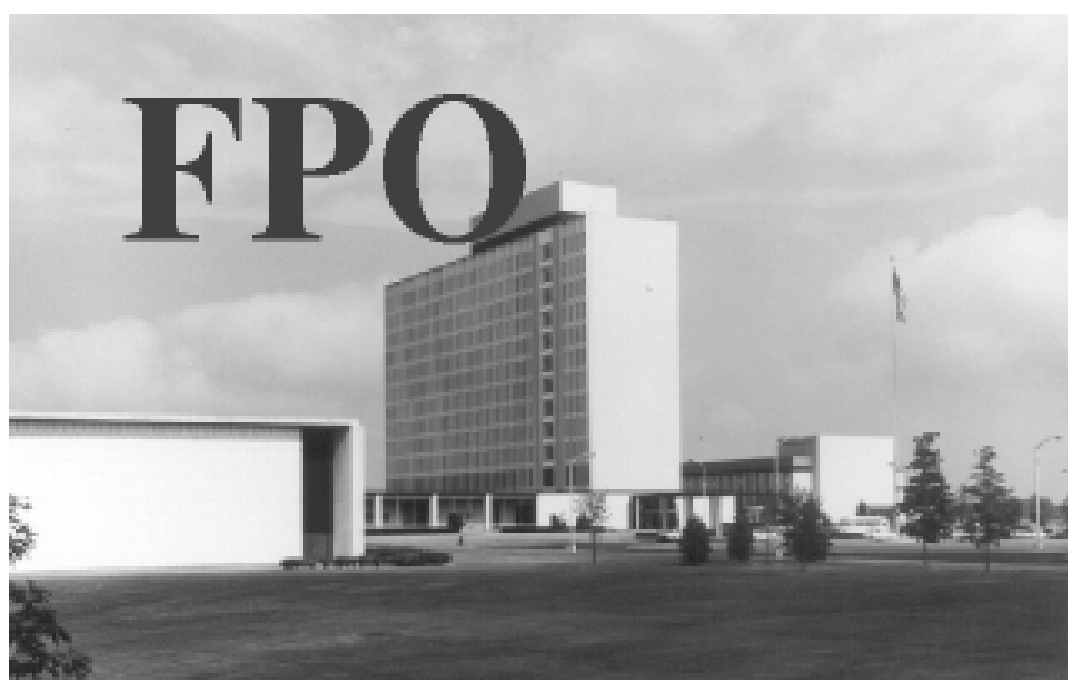

The current administration building of the National Institute of Standards and Technology at Gaithersburg, Maryland.

ratory to the present Gaithersburg, Maryland site took place from 1962 to 1969. In 1951, a new NBS laboratory that specialized in cryogenics research was established in Boulder, Colorado. The Boulder laboratory also housed research on radio propagation and became the home of the Time and Frequency Division.

\section{Scientific Work of NBS/NIST}

Most of the work of NBS/NIST had its origins in standards. Calibration services available from NBS in its early years were limited to mass, length, volume, temperature, electric potential, and resistance. Much of the early scientific equipment was imported with the assistance of the European standards laboratories. However, as NBS expanded its staff and its expertise, this relatively new laboratory rapidly became an equal to the other great standards laboratories. Because standards are almost always international in nature, collaboration with other standards laboratories and organizations has always been an important organizational goal for NBS/ NIST.

Scientific endeavors at NBS/NIST have resulted in two important university collaborations. The first was the Joint Institute for Laboratory Astrophysics (JILA) that was created in 1962 by a memorandum of understanding between NBS and the University of Colorado. The aim of JILA was the study of the basic physics of atoms and molecules in space. The second collaboration was the establishment with the University of Maryland in 1984 of the Center for Advanced Research in Biotechnology (CARB). The main focus of scientific research at CARB is protein chemistry. Currently, structural and theoretical chemistry, molecular biology, and thermodynamics are all applied toward understanding protein structure and function.
NBS programs were clearly affected by national and international events. Thus, NBS played an important role in the early days of government testing. These testing activities included a wide variety of products, many of which were being used by the U.S. Government. However, many of the results of the tests were made available to consumers who benefited from the information. NBS also made significant contributions to the U.S. effort during both world wars. Important breakthroughs were the development of the radio proximity fuse and improved methods for the production of synthetic rubber and aviation fuel. In 1953, the defense programs that had existed at NBS were transferred to the newly created Harry Diamond Ordnance Laboratories and the Navy Corona Laboratory, both in the Department of Defense. While this transfer involved a loss of over one-third of the NBS staff and more than one-half of its budget, it also meant that the work of NBS was now devoted primarily to standards, civilian technology, and science.

A very important change in NIST's interaction with industry came with the Advanced Technology Program, which was established in 1988 to form a partnership with the private sector for the purpose of accelerating the development of innovative technologies that promised significant commercial payoffs and widespread benefits for the nation. An additional NIST program that interacts directly with industry is the Manufacturing Extension Partnership. It consists of a nationwide network of not-for-profit Centers in over 400 locations nationwide. Its purpose is to provide small- and medium-sized manufacturers with access to technical information that can help them succeed. NIST also manages the Malcolm Baldridge National Quality Award, which aims to encourage improvements in manufacturing performance and in the quality of goods and services. The Baldridge Award consists of a prestigious prize given annually to U.S. organizations that have demonstrated performance excellence. The increasing importance of technology in the work of NBS led to a name change. Thus, in 1988 the name of the agency was changed to "National Institute of Standards and Technology" to reflect more accurately the involvement of technology in the work that was being done.

NIST's work is made available to the public in several forms that include calibration services, standard reference materials, standard reference data, and sci- 
entific publications as principal mechanisms for the distribution of services and information. At present, the most widely disseminated standard is time and frequency, which is broadcast from the NIST Boulder laboratory. This information, which is essential to communications and transportation, is now accessed several million times daily. The best source for current information on NIST can be found at its web site: http:// www.nist.gov.

A reasonably complete summary of the work done at NBS/NIST over the past 100 years would have to encompass essentially all aspects of not only chemistry and physics, but also mathematics and statistics, computer science, engineering, and biotechnology. A compendium of summaries of just over 100 of the "most significant publications" from NIST has been prepared for the NIST Centennial from the approximately 100 000 publications that have come from NBS/NIST. Included in these publications are books and journal articles on a wide variety of topics that have had very significant scientific and/or practical impacts. Several of these publications are cited below, together with selected (and edited) narratives from the aforementioned compendium.

N. S. Osborne, H. F. Stimson, D. C. Ginnings. "Calorimetric determination of the thermodynamic properties of saturated water in both the liquid and gaseous states from 100 to $374{ }^{\circ} C^{\prime}$, J. Res. Natl. Bur. Stand. (U.S.) 18, 389-447 (1937). Some of the most important research to meet the need for high-accuracy property data for water was performed at NBS. The effort was led by N. S. Osborne, who, with his colleagues, made measurements of unparalleled accuracy of water's saturation pressure and its thermodynamic properties. While there was a series of papers on the subject, this particular paper is usually considered the most important. These measurements resulted in international standards that, with modifications, are still in use. It is a testimony to the quality of the measurements in this paper that they are still considered the best available over 60 years later. These measurements provide much of the foundation for the "steam tables" used throughout industry. Thus, they have been integral to the design and operation of most electric power generation facilities existing in the world today, and they also continue to be important in many other industries such as chemical manufacturing and petroleum refining.

C. E. Moore. Atomic Energy Levels as Derived from the Analysis of Optical Spectra. Vol. I. Natl. Bur. Stand. (U.S.) Circular 467. U.S. Government Printing Office: Washington, DC (1949). Data on the structure and spectra of atoms is of critical importance for physics, chemistry, astronomy, and a wide variety of applied techni- cal fields. These data are derived largely from the study of optical spectra and have been presented in thousands of research papers beginning in the early 1900s. By the 1940s, it was apparent that there was a need to compile these data in a readily accessible form. This task was undertaken by Dr. Charlotte Moore of NBS, who was joined by several colleagues in later publications. The resulting Atomic Energy Levels volumes have become among the most widely cited and influential publications in atomic physics.

F. D. Rossini, D. D. Wagman, W. H. Evans, S. Levine, I. Jaffe. Selected Values of Chemical Thermodynamic Properties. Natl. Bur. Stand. (U.S.) Circular 500. U.S. Government Printing Office: Washington, DC (1952). Circular 500 represented the culmination of 20 years of work by Frederick Rossini in evaluating and systematizing the world literature in thermochemistry. It tabulated accurate values of the thermodynamic properties of all known inorganic and simple organic compounds in a format that allowed prediction of the outcome of thousands of chemical reactions. Such calculations, which indicate whether a reaction will take place and, if so, the amount of heat released or absorbed, are immensely important in the chemical and energy industries. The late Henry Eyring, one of the major figures of $20^{\text {th }}$ century chemistry, once claimed that Circular 500 saved U.S. industry enough money to pay the entire cost of NBS since its founding. The book also had a major impact on scientific research and education. It was a fixture in every undergraduate chemistry lab for a generation. The U.S. Department of Defense and the National Air and Space Administration programs to develop high-performance rocket engines in the 1950s drew heavily on the data in Circular 500.

W. F. Hillebrand, G. E. F. Lundell, H. A. Bright, J. I. Hoffman. Applied Inorganic Analysis: With Special Reference to the Analysis of Metals, Minerals, and Rocks, (2 ${ }^{\text {nd }}$ ed.), Wiley, New York (1953). This treatise contains an extensive amount of information on classic inorganic chemical separations and quantitative analyses. It helped to shape analytical chemistry worldwide. Six initial chapters describe common analytical methods such as weighing and reagent preparation. In Part II, each element or small group of similar elements has a chapter, giving general chemical considerations, then detailed methods for dissolution, separation, and determination. Nearly 50 years after its publication, there is still no equivalent source for much of the information.

C. S. Wu, E. Ambler, R. W. Hayward, D. D. Hoppes, R. P. Hudson. "Experimental test of parity conservation in beta decay". Phys. Rev. 105, 1413-1415 (1957). From 
the time that parity was introduced as a concept into atomic and nuclear physics, its conservation was an article of faith among physicists. However, it had been pointed out [T. D. Lee and C. N. Yang. Phys. Rev. 104, 254-258 (1956)] that no evidence existed either to support or to refute the conservation of parity in weak interactions. Lee and Yang proposed a number of experiments on beta decays, and on hyperon and meson decays, to resolve the matter, including those of possible asymmetry of the angular distribution of the beta decay of polarized nuclei. This publication reported experiments that showed beta rays that emitted from polarized ${ }^{60} \mathrm{Co}$ atoms, in a thin crystalline layer on single-crystal cerous magnesium nitrate $\left[\mathrm{Ce}_{2} \mathrm{Mg}_{3}\left(\mathrm{NO}_{3}\right)_{12} \cdot 24 \mathrm{H}_{2} \mathrm{O}\right]$ within a demagnetization cryostat, did exhibit this asymmetry, thereby providing unequivocal proof that parity is not preserved. Over preceding years, the authors had developed outstanding theoretical and unexcelled experimental capabilities in this field, so that they were able to grasp the opportunity to carry out the investigation. Its outcome culminated in the Nobel Prize being awarded to Lee and Yang. It also gave NBS well-deserved pride for having participated in one of the major events in the history of physics.

M. Abramowitz and I. A. Stegun (Eds.). Handbook of Mathematical Functions with Formulas, Graphs, and Mathematical Tables. Natl. Bur. Stand. (U.S.) Applied Mathematics Series 55. U.S. Government Printing Office: Washington, DC (1964). This 1046-page handbook provides fundamental reference information about mathematical functions that are of use in many applications. The functions covered include elementary transcendental functions, exponential integrals, the gamma function, Legendre functions, Bessel functions, hypergeometric functions, Coulomb wave functions, elliptic functions, orthogonal polynomials, probability functions, and others. In each case, mathematical properties, such as defining differential equations, recurrence relations, integral representations, summation formulas, and asymptotic expansions, are presented, along with descriptions of computational methods. More than half of the book is devoted to numerical tables of function values. Because of its succinct presentation of information of critical use in applications, the Handbook has had enormous impact on science and engineering. It has been continuously in print since 1964, with total sales estimated at approximately one-half million copies. It is among the most widely cited of all scientific publications.

L. A. Currie. "Limits for qualitative detection and quantitative determination: Application to radiochemistry", Anal. Chem. 40, 586-593 (1968). This classic paper clearly showed the inadequacies of the many definitions of the term "detection limit". A notable example was a figure showing eight literature definitions applied to the same measurement problem that spanned a factor of 500 in the quantity measured. More importantly, the author defined statistically defensible expressions for decision limit, detection limit, and quantitation limit that are now the standard for measurement science. This paper has had more than 1400 citations in the literature and has been used in many analytical chemistry textbooks since the mid-1970s. It has served as a basis for the Detection/Quantification portion of IUPAC Recommendations ["Nomenclature in evaluation of analytical methods including detection and quantification capabilities", Pure Appl. Chem. 67, 1699-1723 (1995)]. Subsequently, these Recommendations were incorporated in the latest edition of the IUPAC "Orange Book".

A. Wlodawer, J. Walter, R. Huber, L. Sjölin. "Structure of bovine pancreatic trypsin inhibitor", J. Mol. Biol. 180, 301-329 (1984). This paper is recognized as a landmark contribution to the field of protein crystallography. It was the first publication to combine X-ray and neutron data in the joint refinement of protein structure, and the first to extend spatial resolution of hydrogen positions in small proteins to $<10^{-10} \mathrm{~m}$. By describing the study of two similar crystal structures, the paper presented the first detailed analysis of how protein structure is affected by molecular packing. This paper also established that joint X-ray-neutron refinement could produce structural detail consistent with the thenemerging technique of 2-dimensional nuclear magnetic resonance (NMR) protein crystallography. Thus, this publication had a notable impact on the field of protein crystallography.

P. D. Lett, R. N. Watts, C. I. Westbrook, W. D. Phillips, P. L. Gould, H. J. Metcalf. "Observation of atoms laser cooled below the Doppler limit”. Phys. Rev. Lett. 61 , 169-172 (1988). This paper is one of a series of papers that reported scientific breakthroughs in the cooling and trapping of atoms that led to Bill Phillips being a corecipient of the 1997 Nobel Prize in Physics. By the time of this paper, Phillips and a coworker had shown how an atom beam could be slowed by an opposing laser beam if a varying magnetic field kept the atoms in resonance by compensating for the changing Doppler shift as the atoms decelerated. Phillips and coworkers had also reported the first observation of electromagnetically trapped neutral atoms. However, and most importantly, what was thought to be a fundamental theoretical lower limit on laser cooling of atoms, the Doppler limit, was shown to be violated in this paper. This very surprising discovery resulted from investigations to obtain a better understanding of the basic nature of 
the optical cooling process. The result was so surprising that Phillips and coworkers spent considerable time testing the measurement system to make sure that it was working properly. They then determined the velocity distribution of the atoms (and, therefore, the temperature) four different ways before submitting the paper for publication. This work furthered our understanding of the interaction between light and matter and pointed the way for a refined theory to explain these surprising results. Additionally, the possibility of trapping atoms and cooling them to very low temperatures has opened up new science and applications. The present generation of atomic clocks, based on atomic fountains, would not have been possible without sub-Doppler cooling. Ultracold atoms, which have very long de Broglie wavelengths, have given rise to new research fields such as atom optics, atom interferometry, optical lattices, and Bose-Einstein condensation of dilute gases.

This compendium of summaries of NBS/NIST's "most significant publications" has been published under the title A Century of Excellence in Measurements, Standards, and Technology: A Chronicle of Selected NBS/ NIST Publications, 1901-2000, edited by David R. Lide (NIST Special Publication 948, U.S. Department of Commerce, Technology Administration, National Institute of Standards and Technology, Washington, DC, for sale by the Superintendent of Documents, U.S. Government Printing Office, 2001). Additional NBS/ NIST publications included in the book that are of interest to chemists cover the discovery of deuterium, accurate measurements of the gas constant, the photochemistry of small molecules, electron probe microanalysis, advances in surface science, and the behavior of fluids, particularly in the critical region. A general review of NBS/NIST's impact on the $20^{\text {th }}$ century is NIST at 100: Foundations for Progress, by Laura Ost (NIST Special Publication 956, U.S. Department of Commerce, Technology Administration, National Institute of Standards and Technology, Washington, DC, for sale by the Superintendent of Documents, U.S. Government Printing Office, 2001).

\section{NBS/NIST Participation in IUPAC}

Many scientists on the NBS/NIST staff have participated in IUPAC projects as members of Commissions,

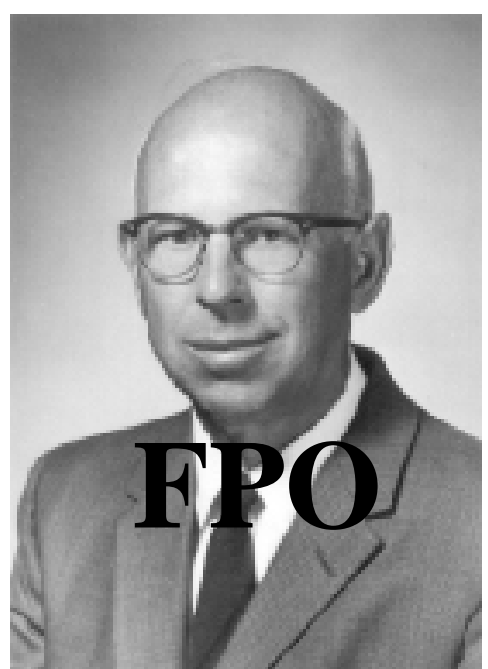

eft: Frederick Rossini, an NBS scientist who helped establish the IUPAC Commission on Chemical Thermodynamics (I.2). Rossini was also the Thermodynamic Properties. Right: Roger G. Bates, an NBS scientist who played an important role in the development of the $\mathrm{pH}$ scale.

Committees, and Subcommittees. Frederick D. Rossini helped establish the Commission on Thermodynamics (I.2). A particularly impressive record is that of Roger G. Bates, who served on three different Commissions as well as on the Analytical Chemistry Division (V) Committee. His tenure with IUPAC lasted 30 years (1953-1983). A selected, but by no means complete, list of NBS/NIST participants in IUPAC is given below, with emphasis on the past 20 years.

\section{Physical Chemistry Division (I)}

\section{Subcommittee on Reference Materials}

Stanley D. Rasberry

Commission on Physicochemical Symbols,

Terminology, and Units (I.1)

David R. Lide (also President of Physical Chemistry Division, 1983-1987; Chairman of Committee on Chemical Databases, 1985-1989)

Roger G. Bates

William H. Kirchhoff

Commission on Thermodynamics (I.2)

George T. Armstrong

Eugene S. Domalski

Robert N. Goldberg

Peter L. M. Heydemann

Patrick A. G. O’Hare (Chairman, 1989-1995; also served on Physical Chemistry Division Committee, 1996-1999)

Edward J. Prosen 
Frederick D. Rossini (led the Commission and its predecessor bodies from 1946-1961)

Howard J. White

Commission on Electrochemistry (I.3)

Roger G. Bates

Commission on Chemical Kinetics (I.4)

Robert F. Hampson

John T. Herron (Chairman, 1993-1997)

Robert E. Huie

Commission on Molecular Structure and Spectroscopy (I.5)

John T. Hougen

Commission on Colloid and Surface Chemistry

Including Catalysis (I.6)

Cedric J. Powell

Commission on Biophysical Chemistry (I.7)

Robert N. Goldberg (Secretary, 1996-2001)

Frederick D. Schwarz

\section{Inorganic Chemistry Division (II)}

Edward Wichers (President, 1955-1957)

Commission on Atomic Weights and Isotopic Abundances (II.1)

I. Lynus Barnes

Harry S. Hertz

Thomas J. Murphy

H. Steffen Peiser

Robert D. Vocke (Secretary, 1996-1997)

Commission on High Temperature Materials and Solid State Chemistry (II.3)

John W. Hastie

Commission on Isotope Specific Measurements as

Traceable References (II.4)

John R. Moody

Robert D. Vocke

\section{Analytical Chemistry Division (V)}

Commission on Analytical Nomenclature (formerly V.3/V.1)

Lloyd A. Currie (also served on the Analytical Chemistry Division Committee, 1994-2001)

Commission on Spectrochemical and Other Optical

Procedures for Analysis (V.4)

Gregory C. Turk
Commission on Electroanalytical Chemistry (V.5)

Roger G. Bates (Chairman; also served on Analytical Chemistry Division Committee)

Richard A. Durst (also served on Analytical Chemistry Division Committee, 1991-2001)

William F. Koch

Kenneth W. Pratt

Commission on Solubility Data (V.8)

Lewis H. Gevantman (Secretary, 1983-1991)

\section{Events to Mark the Centennial}

The week of 1-8 March 2001 was designated as "Centennial Week" at NIST. Major events held at NIST (Gaithersburg and Boulder laboratories) during that week included the following:

- NIST Boulder's accomplishments and outlook, March 1 (Boulder)

- NIST history and opening Centennial SymposiumReunion Day for NIST staff and alumni, March 5 (Gaithersburg and Boulder)

- Gala celebration, Ronald Reagan International Trade Center, Washington, DC, evening of March 6

- Symposium on Standards in the Global Economy: A Changing Future, March 7 (Gaithersburg)

- Meeting of the National Metrology Institute Directors (Gaithersburg), March 8

Approximately 65 scientific societies and professional organizations have events to mark the NIST Centennial. These societies include the American Institute of Chemical Engineers, the American Physical Society, the Electrochemical Society, and the Pittsburgh Conference. IUPAC has marked the NIST Centennial by means of a symposium on standards at the $16^{\text {th }}$ IUPAC Conference on Chemical Thermodynamics that was held 6-11 August 2000 in Halifax, Nova Scotia, Canada. Additionally, a session on "Standards and Measurement: Future Directions" will be featured at the World Chemistry Congress to be held 1-6 July 2001 in Brisbane, Australia. 